\title{
Iron(III) Chloride mediated reduction of Bis(1-isoquinolylcarbonyl)amide to an Amide ${ }^{\dagger}$
}

\author{
ROJALIN SAHU ${ }^{\mathrm{a}, \mathrm{b}}$, PAPULI CHALIHA ${ }^{\mathrm{a}}$ and VADIVELU MANIVANNAN ${ }^{\mathrm{a}, *}$ \\ ${ }^{a}$ Department of Chemistry, Indian Institute of Technology Guwahati, Guwahati 781 039, India \\ ${ }^{\mathrm{b}}$ School of Applied Sciences (Chemistry), Campus-3, KIIT UNIVERSITY, Patia, \\ Bhubaneswar 751 024, India \\ e-mail: mani@iitg.ernet.in
}

MS received 8 August 2015; revised 15 October 2015; accepted 19 October 2015

\begin{abstract}
In methanol, $\mathrm{FeCl}_{3}$ reacted readily with $\mathbf{L 1 H}(\mathbf{L 1 H}=$ bis(1-isoquinolylcarbonyl)amide $)$ and afforded a complex having the formula $\left[\mathrm{Fe}(\mathbf{L} 2) \mathrm{Cl}_{2}\right](\mathbf{1})\left\{\mathbf{L 2}^{-}=N-((1\right.$-isoquinolyl)(methoxy)methyl)isoquinoline1-carboxamide ion $\}$. This reaction involves reduction of one of the two carbonyl groups present in $\mathbf{L 1 H}$ to (methoxy)methyl group. A plausible mechanism for the conversion of $\mathbf{L} \mathbf{1 H}$ to $\mathbf{L} \mathbf{2}^{-}$has been proposed. Determination of molecular structure of $\mathbf{1}$ confirmed this conversion. Fe(III) ion is surrounded by three nitrogen atoms of the ligand and two chloride ions, imparting a rare distorted trigonal bipyramidal $\mathrm{N}_{3} \mathrm{Cl}_{2}$ coordination environment.
\end{abstract}

Keywords. Reduction; Ferric chloride; Isoquinoline; Bis(carbonyl)amide.

\section{Introduction}

Iron(III) chloride has been known to catalyze or assist several kinds of organic reactions. ${ }^{1-3}$ This includes Friedel-Crafts, ${ }^{4,5}$ Michael addition, ${ }^{6-8}$ Ritter, ${ }^{9}$ alkylation of indoles with enamides ${ }^{10,11}$ and oxidation of thiols (RSH) to RSSR in the presence of butadiene. ${ }^{12}$ Oxidation of alkanes by $\left[\mathrm{Os}(\mathrm{N}) \mathrm{O}_{3}\right]^{-}$ion, ${ }^{13}$ coupling of $\mathrm{ArMgX}$ with alkyl halides, ${ }^{14}$ synthesis of polysubstituted benzofurans (a component in the synthesis of coumarins by Pechmann condensation) using di-tertbutyl peroxide, phenols and $\beta$-keto esters ${ }^{15}$ were reported. Oxygenation of cycloalkanones to oxo esters, ${ }^{16}$ oxidative coupling reactions of phenols ${ }^{17}$ and disproportionation of allylic alcohols ${ }^{18}$ were achieved using iron(III) chloride. Alkenylation of simple arenes with aryl-substituted alkynes, ${ }^{19}$ synthesis of sulfonyl amidines ${ }^{20} \alpha$-glycosidation, ${ }^{21}$ synthesis of indene derivatives, ${ }^{22} 1,4$-addition of various thiols to $\alpha, \beta$-unsaturated ketones, ${ }^{23}$ preparation of cyanohydrin esters, ${ }^{24}$ protection of diols and carbonyls ${ }^{25}$ as well as formation of $\beta$-nitroalcohols ${ }^{26}$ have also been reported.

We recently reported ${ }^{27}$ the formation of bis(1-isoquinolylcarbonyl)amide (L1H) from 1-aminomethylisoquinoline in presence of copper(II) acetate and were

\footnotetext{
*For correspondence

${ }^{\dagger}$ Dedicated to Professor Animesh Chakravorty on the occasion of his $80^{\text {th }}$ birth anniversary.
}

exploring the reaction of $\mathbf{L 1 H}$ with other transition metal ions. Herein we report a facile reaction of $\mathbf{L 1 H}$ with $\mathrm{FeCl}_{3}$ that led to the formation of $\left[\mathrm{Fe}(\mathbf{L 2}) \mathrm{Cl}_{2}\right]$ under ambient conditions, wherein $\mathbf{L 2}^{-}=N$-((1-isoquinolyl)(methoxy)methyl)isoquinoline-1-carboxamide ion. This new iron(III) complex of the transformed ligand $\left(\mathbf{L 2}^{-}\right)$was not accessible by conventional methods.

\section{Experimental}

\subsection{Materials and methods}

Anhydrous $\mathrm{FeCl}_{3}$ (Merck India Ltd) and other reagent grade chemicals were used as received without further purification. Bis(1-isoquinolylcarbonyl)amide (L1H) was prepared using the reported procedure..$^{27,28}$

A Perkin-Elmer Spectrum One FT-IR spectrometer (4000-250 $\mathrm{cm}^{-1}$ ), Perkin-Elmer Lambda 25 UV-Vis spectrometer, Perkin-Elmer Series II CHNS/O Analyzer 2400, JEOL JES FA-200 X-band EPR spectrometer, and a Lakshore VSM Setup were used for performing relevant measurements.

X-ray crystallographic data were collected using Bruker SMART APEX-CCD diffractometer with Mo $\mathrm{K} \alpha$ radiation $(\lambda=0.71073 \AA)$. The intensity data were corrected for Lorentz and polarization effects and empirical absorption corrections was applied using SAINT program. ${ }^{29}$ The structure was solved by direct 
methods using SHELXS-97. ${ }^{30,31}$ Non-hydrogen atoms located from the difference Fourier maps were refined anisotropically by full-matrix least-squares on $\mathrm{F}^{2}$ using SHELXL-97. ${ }^{30,31}$ All hydrogen atoms were included at the calculated positions and refined isotropically using a riding model.

\subsection{Synthesis}

2.2a $\left[\mathrm{Fe}\left(\mathrm{L2}_{2} \mathrm{Cl}_{2}\right](1)\right.$ : To a methanolic solution $(20 \mathrm{~mL})$ of $\mathrm{FeCl}_{3}(16.0 \mathrm{mg}, 0.1 \mathrm{mmol})$ solid $\mathbf{L 1 H}(33.0 \mathrm{mg}$, $0.1 \mathrm{mmol}$ ) was added and stirred for $8 \mathrm{~h}$. The reaction mixture was left undisturbed and after 4 days red crystals of 1 were isolated. Yield: $30.0 \mathrm{mg}, 64 \%$. IR $(\mathrm{KBr})$ $v_{\max }\left(\mathrm{cm}^{-1}\right): 3438,1719,1651,1618,1588,1500,1449$, 1432, 1394, 1382, 1356, 1331, 1289, 1255, 1190, 1152, 1092, 1054, 1017, 903, 878, 867, 824,750, 672, 654, 628, 609, 572, 507, 489, 473, 415, 386, 356. Anal. calcd for $\mathrm{C}_{21} \mathrm{H}_{16} \mathrm{~N}_{3} \mathrm{O}_{2} \mathrm{Cl}_{2} \mathrm{Fe}$ : C 53.77; H 3.44; $\mathrm{N} 8.96 \%$. Found: C 53.57; H 3.40; N 8.89\%. UV-Vis $\left[\lambda_{\max }\right.$, $\left.\mathrm{nm}\left(\varepsilon, \mathrm{M}^{-1} \mathrm{~cm}^{-1}\right), \mathrm{MeOH}\right]: 370(9425), 335(15180)$, 325(15570). EPR (DMF solution, $77 \mathrm{~K}): g_{\text {eff }}=4.27$; $\mu_{\text {eff }}$ (polycrystalline, $25^{\circ} \mathrm{C}$ ) $=5.60$ B.M.

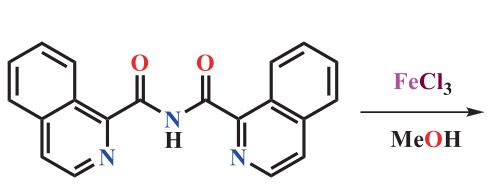

L1H<smiles></smiles>

1

Scheme 1. Synthesis.

\section{Results and Discussion}

\subsection{Synthesis}

On stirring $\mathbf{~} \mathbf{1 H}$ with anhydrous $\mathrm{FeCl}_{3}$ in methanol, a yellowish red solution was obtained, which on standing afforded red crystals of $\mathbf{1}$. The molecular structure of $\mathbf{1}$ has been determined (vide infra) and the composition $\left[\mathrm{Fe}(\mathbf{L} 2) \mathrm{Cl}_{2}\right]$ has been formulated (scheme 1). During the course of the reaction, reactivity at the carbonyl function of the ligand has been enhanced upon coordination and one of the two carbonyl groups of bis(1-isoquinolylcarbonyl)amide has been reduced ${ }^{32}$ to (methoxy)methyl group. It is relevant to note that bis(2-pyridylcarbonyl)amine (L3H) having a similar ligand framework has been reported to react with $\mathrm{FeCl}_{3}$ resulting in the formation of $\left[\mathrm{Fe}(\mathbf{L} \mathbf{3}) \mathrm{Cl}_{2}\left(\mathrm{H}_{2} \mathrm{O}\right)\right]$ and $\left[\mathrm{Fe}(\mathbf{L} \mathbf{3})_{2}\right]^{+}$species, without any change in $\mathbf{L} 3 \mathbf{H} .{ }^{33}$ To the best of our knowledge this is the first example of reduction of dicarbonylamides, in which one carbonyl group has been converted to a (methoxy)methyl group.

\subsection{Plausible mechanism}

A plausible mechanism for this conversion has been proposed in scheme 2. First step is formation of

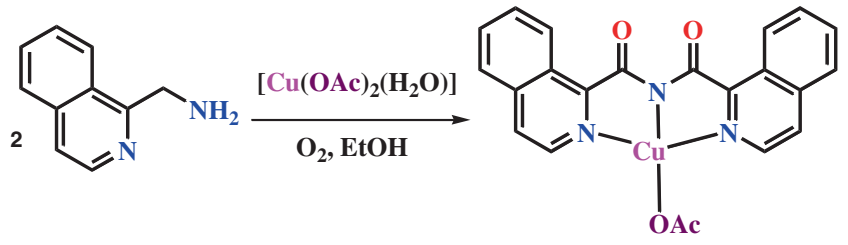

Scheme 3. Formation of L1H from 1-aminomethylisoquinoline.

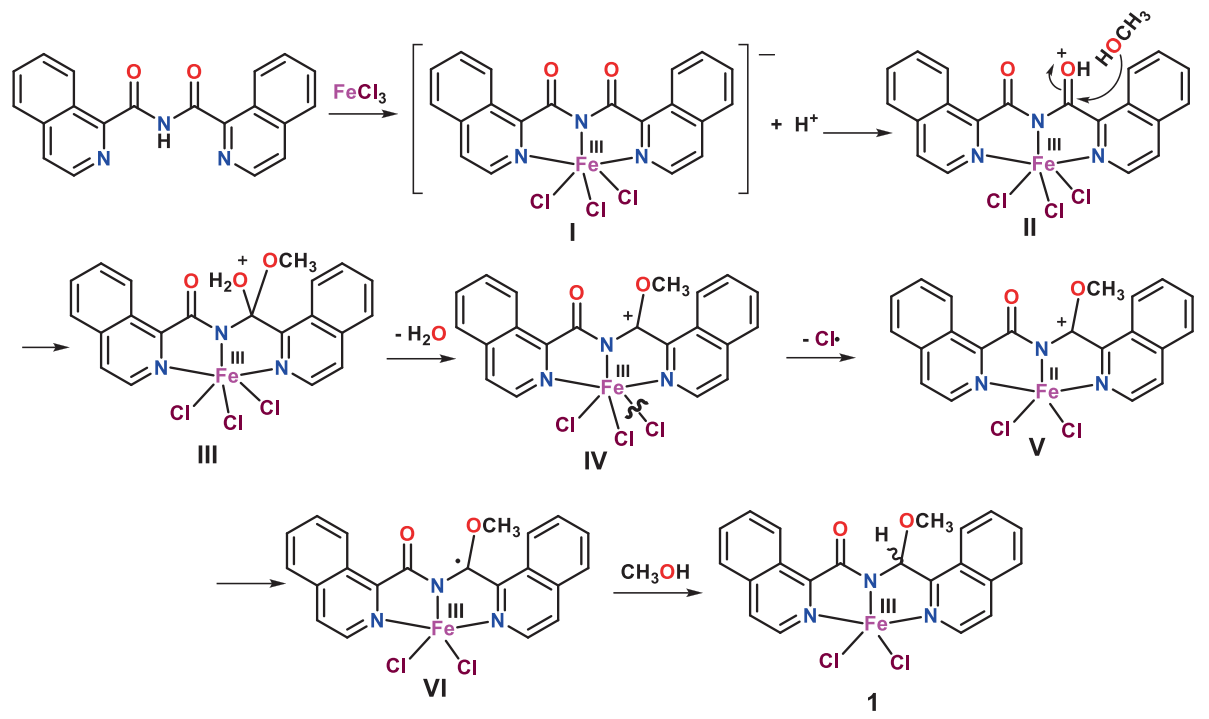

Scheme 2. Plausible mechanism for the formation of $\mathbf{1}$ from $\mathbf{L 1 H}$. 
simple monochelate of $\mathbf{L 1}^{-}$having the composition $\left[\mathrm{Fe}(\mathbf{L} \mathbf{1}) \mathrm{Cl}_{3}\right]^{-}$(I). Upon reaction of $\mathrm{FeCl}_{3}$ with $\mathbf{L 1 H}$ a proton will be released which will attach to one of the carbonyl oxygen atoms as in II. This will polarize the carbonyl group, which will become susceptible to nucleophilic attack by $\mathrm{CH}_{3} \mathrm{OH}$ molecule and a concomitant proton shift will lead to intermediate III. Elimination of a water molecule from III will yield cation IV, which could undergoes a homolytic cleavage at one of the $\mathrm{Fe}(\mathrm{III})-\mathrm{Cl}$ bonds. This will release a $\mathrm{Cl}$ atom and intermediate $\mathbf{V}$ containing five-coordinated iron(II) center. Iron(II) could transfer one electron to the electrophilic carbon to generate a radical intermediate VI, containing five-coordinated iron(III) center. This radical could abstract $\mathrm{H}$ atom from $\mathrm{MeOH}$ leading to the final product $\mathbf{1}$.

It is also important to note here that different dicarbonylamides are formed from appropriately substituted pyridine nucleus having an ortho aminomethyl group in presence of copper(II) acetate. ${ }^{30,31}$ This conversion involves oxidation of the methylene group and coupling of the bond between nitrogen and carbon in $\mathrm{N}-\mathrm{C}(=\mathrm{O})$. However, thus formed (from 1-aminomethylisoquinoline in presence of copper(II) acetate, scheme 3) dicarbonyl group in $\mathbf{L 1 H}$ undergoes a reduction in presence of iron(III) chloride. It is also important to note that penta-coordinated iron(III) complexes find application as efficient catalysts for the cross-coupling reaction between arylmagnesium bromides and alkyl halides. ${ }^{34,35}$

\subsection{Optical Spectra and Magnetism}

The IR spectrum of free L1H shows $v_{\mathrm{CO}}$ around $1745 \mathrm{~cm}^{-1}, 30,31$ which is lowered to the range 1690$1710 \mathrm{~cm}^{-1}$ upon coordination to a metal center as observed in the complexes $\left[\mathrm{Cu}(\mathbf{L 1})\left(\mathrm{H}_{2} \mathrm{O}\right)_{2}\right] \mathrm{ClO}_{4}$ and $\left[\mathrm{Ni}(\mathbf{L 1})_{2}\right]$. Compound $\mathbf{1}$ shows a characteristic $1719 \mathrm{~cm}^{-1}$ peak for $v_{\mathrm{CO}}$. In addition, a strong peak for $v_{\mathrm{C}-\mathrm{O}}$ at $\sim 1250 \mathrm{~cm}^{-1}$ and $v_{\mathrm{Fe}-\mathrm{Cl}}$ peaks at $\sim 386$ and 356 $\mathrm{cm}^{-1}$ were noted. Methanol solution of $\mathbf{1}$ shows allowed transitions in the UV region with the peak at 370 $\mathrm{nm}$ tailing into visible region and thus accounting for red/yellow color of compound. Since in the case of high-spin $d^{5}$ complexes, $d$ - $d$ transitions are both Laporte and spin forbidden, such transitions are not observed in $\mathbf{1}$. The room temperature magnetic moment of polycrystalline samples of $\mathbf{1}$ has the value of 5.60 B. $\mathrm{M}$. which is less than the spin-only value of 5.92 B.M. At $77 \mathrm{~K}$, EPR spectrum of $\mathbf{1}$ (DMF solution) shows a

Table 1. Crystallographic Data for $\mathbf{1}$.

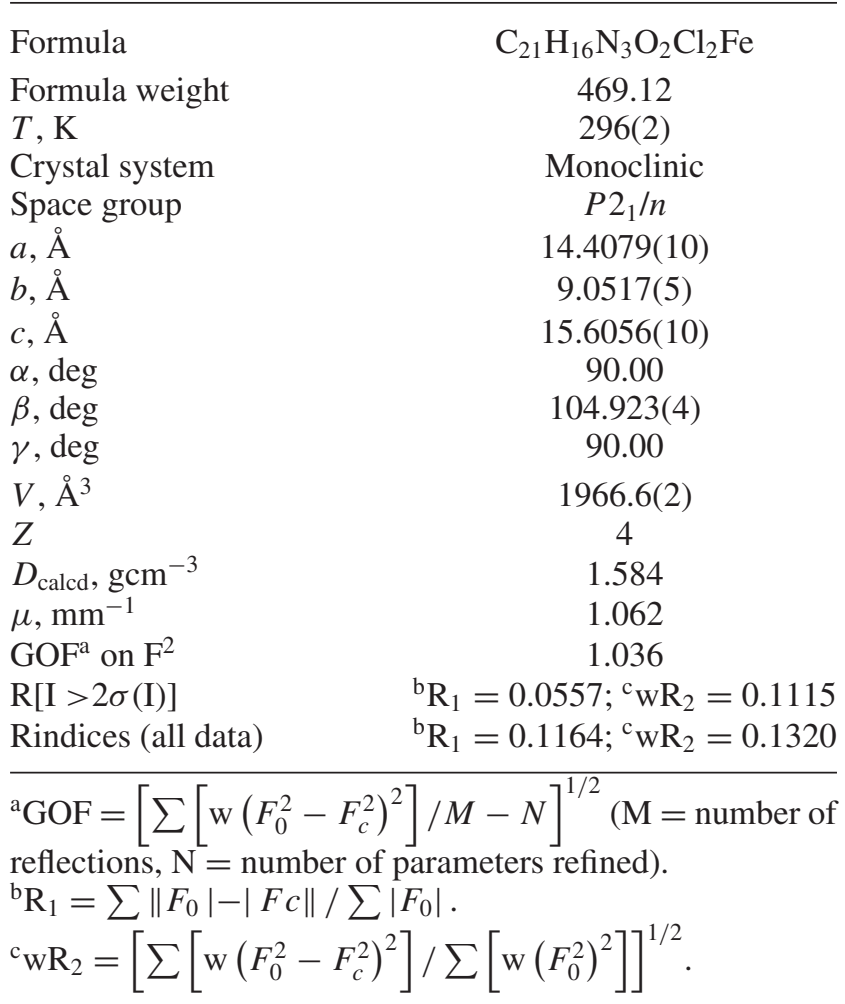

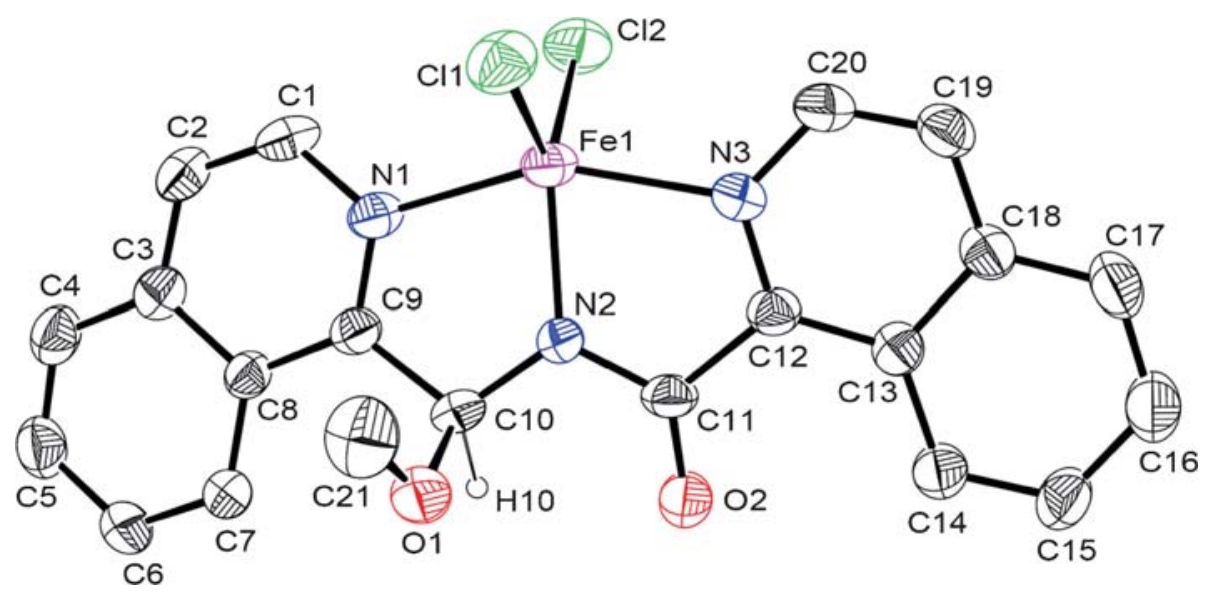

Figure 1. ORTEP (30\% probability ellipsoids) diagram of 1; hydrogen atoms except H10 were omitted for clarity. 
broad signal centered at $g_{\text {eff }}=4.27$. These features are consistent with the presence of high-spin $d^{5}$ iron(III) center. ${ }^{33}$

\subsection{Molecular Structure}

The molecular structure of $\mathbf{1}$ has been determined by single crystal X-ray diffraction method and its ORTEP diagram is displayed in figure 1 . The crystallographic data and selected bond parameters are listed in tables 1 and 2, respectively. The compound crystallized in $P 2_{1} / n$ space group and the trivalent iron is penta-coordinated with $\mathbf{L} \mathbf{2}^{-}$bound as an end-cap tridentate chelating ligand. The geometry around Fe(III) can be best described as distorted trigonal bipyramidal containing a unique $\mathrm{N}_{\mathrm{C}}\left(\mathrm{N}_{\mathrm{E}}\right)_{2} \mathrm{Cl}_{2}\left(\mathrm{~N}_{\mathrm{C}}=\right.$ amide- $\mathrm{N}$; $\mathrm{N}_{\mathrm{E}}=$ pyridyl-N) distorted trigonal plane having angles

Table 2. Selected bond distances $(\AA)$ and angles $\left({ }^{\circ}\right)$.

\begin{tabular}{llcc}
\hline Fe1-N1 & $2.125(4)$ & N2- Fe1-N1 & $77.51(16)$ \\
Fe1-N2 & $1.953(3)$ & N2- Fe1-N3 & $76.86(16)$ \\
Fe1-N3 & $2.130(4)$ & N1- Fe1-N3 & $153.62(16)$ \\
Fe1-Cl1 & $2.210(2)$ & N2- Fe1-Cl1 & $120.70(12)$ \\
Fe1-Cl2 & $2.212(2)$ & N1- Fe1-Cl1 & $99.14(11)$ \\
O1-C10 & $1.428(5)$ & N3- Fe1-Cl1 & $99.19(11)$ \\
O1-C21 & $1.474(6)$ & N2- Fe1-Cl2 & $127.37(12)$ \\
O2-C11 & $1.223(4)$ & N1- Fe1-Cl2 & $95.31(12)$ \\
C10-N2 & $1.435(6)$ & N3- Fe1-Cl2 & $95.25(12)$ \\
C11-N2 & $1.354(5)$ & Cl1- Fe1-Cl2 & $111.93(6)$ \\
& & C10-O1-C21 & $114.1(4)$ \\
& & C11-N2-C10 & $117.0(4)$ \\
& & N2-C10-O1 & $114.0(4)$ \\
& & O2-C11-N2 & $125.2(5)$ \\
& & C12-C11-O2 & $122.3(5)$ \\
& & N2-C10-C9 & $108.8(4)$ \\
& & C12-C11-N2 & $112.5(4)$ \\
\hline
\end{tabular}

Table 3. Comparison of bond distances.

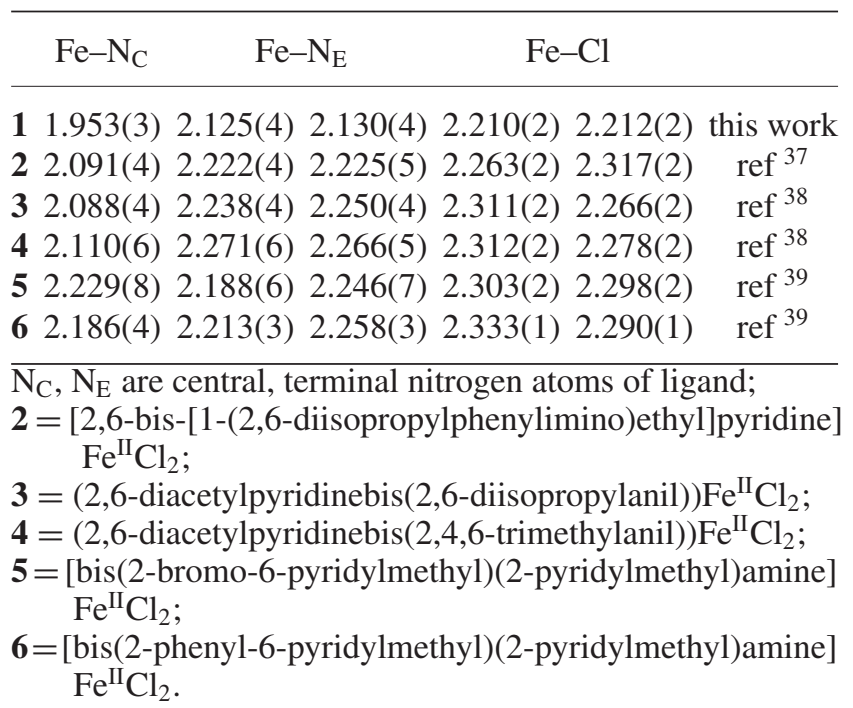

Cl1-Fe1-N2, 120.70(9) ${ }^{\circ}$; Cl2-Fe1-N2, 127.38(9) and $\mathrm{Cl1}-\mathrm{Fe} 1-\mathrm{Cl} 2,111.91(5)^{\circ}$. As a result of severe distortion in the axial N1-Fe1-N3 angle $\left(153.6(1)^{\circ}\right)$, the calculated $\tau$ value of 0.44 is less significant in inferring the geometry. ${ }^{36}$ The $\mathrm{Fe}-\mathrm{N}_{\mathrm{C}}$ bond is shorter than the two $\mathrm{Fe}-\mathrm{N}_{\mathrm{E}}$ bonds by an average of $0.176(3) \AA$, which can be ascribed to geometrical constraints of the ligand framework. Such a trend in which the central bond of a end-cap tridentate chelating ligand bearing geometrical constraints, being shorter than the other two, has also been observed in $\mathrm{Fe}^{\mathrm{II}}$ complexes of bis(imino)pyridines having the closely related coordination environment $\mathrm{Fe}^{\mathrm{II}} \mathrm{N}_{3} \mathrm{Cl}_{2} .{ }^{37,38}$ However such a discrepancy was not observed in complexes having flexible tripodal ligand framework. ${ }^{39}$ Overall, the $\mathrm{Fe}^{\mathrm{III}}-\mathrm{N}$ distances observed in this rare example are shorter than the reported $\mathrm{Fe}^{\mathrm{II}}-\mathrm{N}$ values. Two $\mathrm{Fe}^{\mathrm{III}}-\mathrm{Cl}$ bonds having a length of 2.210(2) and 2.212(2) $\AA$ are shorter than that found (lying in the range 2.266(2)-2.312(2) $\AA$ ) in closely related five-coordinated bivalent iron complex having a similar $\mathrm{Fe}^{\mathrm{II}} \mathrm{N}_{3} \mathrm{Cl}_{2}$ coordination environment reported earlier. ${ }^{37,38}$ In table $3, \mathrm{Fe}-\mathrm{N}$ and $\mathrm{Fe}-\mathrm{Cl}$ bond distances are listed for ready comparison. It is also relevant to note that $\mathrm{C} 10-\mathrm{O} 1(1.428(5) \AA)$ distance is longer than that of $\mathrm{C} 11-\mathrm{O} 2(1.223(5) \AA)$.

The methyl of methoxy group is uniquely projected towards the metal center having the non-bonded contacts $\mathrm{C} 21 \cdots \mathrm{Fe} 1,3.997(5) \AA$ and $\mathrm{C} 21 \ldots \mathrm{Cl} 1,4.213(5)$ $\AA$. In the packing diagram, $\pi \cdots \pi$ interaction is present having the following $c \mathrm{c} \cdots \mathrm{cg}(\mathrm{cg}=$ centroid $)$ contacts: N1C2C3C 8 C 9 with $\mathrm{N} 3 \mathrm{C} 12 \mathrm{C} 13 \mathrm{C} 18 \mathrm{C} 19 \mathrm{C} 20$, $3.84 \AA$; $122 \mathrm{C} 3 \mathrm{C} 8 \mathrm{C} 9$ with $\mathrm{C} 13-\mathrm{C} 18,3.89 \AA$; C4-C8 with C13-C18, 3.94 A; C4-C8 with N3C12C13C18C19C20, $3.95 \AA$. These $\pi \cdots \pi$ interactions and an intermolecular short contact $(\mathrm{C} 4 \cdots \mathrm{C} 12$, $3.378(6) \AA$ ) lead to a chain composed of same enantiomers. A perspective view of the packing diagram is shown in figure 2 . An intermolecular contact $\mathrm{C} 7 \cdots \mathrm{O} 2$,

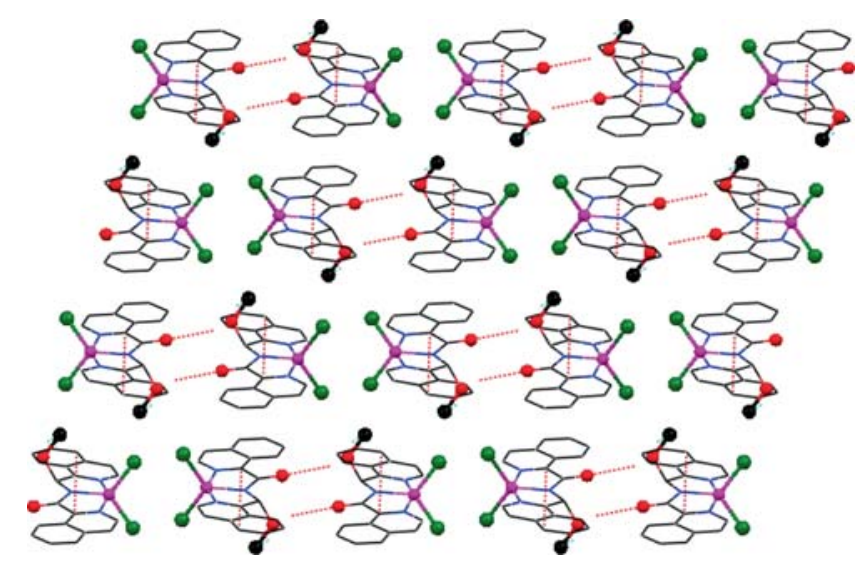

Figure 2. Packing diagram on viewing down $b$-axis. 


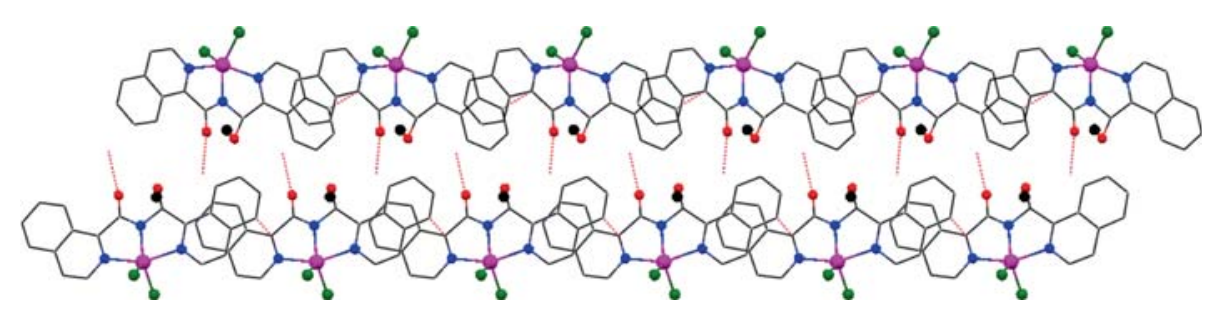

Figure 3. Double stranded chain.

3.251(6) $\AA$, is present between the chains which link two chains containing opposite chiral carbon atoms in head-to-head fashion to double stranded chains (figure 3). Within a double strand, isoquinolyl rings are tilted such that inter-strand angle between planes of two isoquinolyl rings is $38.18^{\circ}$ and between two planes of chelated ring Fe1N1C $9 \mathrm{C} 10 \mathrm{~N} 2 \mathrm{C} 11 \mathrm{C} 12 \mathrm{~N} 3$ is $48.54^{\circ}$.

\section{Conclusions}

The ligand $\mathbf{L 1 H}$ reacted readily with anhydrous $\mathrm{FeCl}_{3}$ in methanol yielding red crystals of composition $\left[\mathrm{Fe}(\mathbf{L 2}) \mathrm{Cl}_{2}\right]$ in which $\mathbf{L 2}^{-}$is $N$-((1-isoquinolyl) (methoxy)methyl)isoquinoline-1-carboxamide ion. In this reaction, one of the two carbonyl groups in $\mathbf{L 1 H}$ has been reduced to a (methoxy)methyl group. Thus, it is important to note that iron(III) chloride reduces L1H but copper(II) acetate favours formation of the same from 1-aminomethylisoquinoline. Compound $\mathbf{1}$ is a rare example of penta-coordinated iron(III) complex having $\mathrm{N}_{3} \mathrm{Cl}_{2}$ environment with a distorted trigonal bipyramid geometry.

\section{Supplementary Information (SI)}

CCDC number 987001 contains the supplementary crystallographic data for complex $\mathbf{1}$. This data can be obtained free of charge via http://www.ccdc.ac.uk/ conts/retrieving.html or from the Cambridge Crystallographic Data Centre, 12 Union Road, Cambridge CB2 1EZ, UK; fax: (+44) 1223-336-033; or e-mail: deposit@ccdc.cam.ac.uk. IR spectrum of $\mathbf{1}$ is provided which is available at www.ias.ac.in/chemsci.

\section{Acknowledgements}

We are grateful to the Department of Science and Technology (DST), New Delhi, for financial grant and establishing the single crystal X-ray diffractometer facility under FIST scheme. The authors are thankful to Dr. Babulal Das for the X-ray data.

\section{References}

1. Bolm C, Legros J, Le Paih J and Zani L 2004 Chem. Rev. 1046217

2. Plietker B 2008 In Iron Catalysis in Organic Chemistry: Reactions and Applications (Weinheim: Wiley$\mathrm{VCH})$

3. Stamatatos T C, Efthymiou C G, Stoumpos C and Perlepes S P 2009 Eur. J. Inorg. Chem. 3361

4. Thirupathi P and Kim S S 2010 J. Org. Chem. 755240

5. Csihony S, Mehdi S S, Homonnay Z, Vértes A, Farkas Ö and Horváth I T 2002 J. Chem. Soc., Dalton Trans. 680

6. Kidwai M, Mishra N K, Bansal V, Kumar A and Mozumdar S 2009 Tetrahedron Lett. 501355

7. Christoffers J 1997 Chem. Commun. 943

8. Li H, Xu X, Yang J, Xie X, Huang H and Li Y 2011 Tetrahedron Lett. $\mathbf{5 2} 530$

9. Anxionnat B, Guérinot A, Reymond S and Cossy J 2009 Tetrahedron Lett. 503470

10. Niu T, Huang L, Wu T and Zhang Y 2011 Org. Biomol. Chem. 9273

11. Li R, Wang S R and Lu W 2007 Org. Lett. 92219

12. Jenner B E L and Lindsey Jr. R V $1960 \mathrm{~J}$. Am. Chem. Soc. 831911

13. Yiu S, Wu Z, Mak C and Lau T 2004 J. Am. Chem. Soc. 12614921

14. Noda D, Sunada Y, Hatakeyama T, Nakamura M and Nagashima H 2009 J. Am. Chem. Soc. 1316078

15. Stoyanovsky D A, Clancy R and Cederbaum A I $1999 \mathrm{~J}$. Am. Chem. Soc. 1215093

16. Trost B M and Ornstein P L 1983 J. Org. Chem. 481133

17. Toda F, Tanaka K and Iwata S 1989 J. Org. Chem. 54 3007

18. Wang J, Huang W, Zhang Z, Xiang X, Liu R and Zhou X 2009 J. Org. Chem. 743299

19. Li R, Wang S R and Lu W 2007 Org. Lett. 92219

20. Wang S, Wang Z and Zheng X 2009 Chem. Commun. 7372

21. Chatterjee S K and Nuhn P 1998 Chem. Commun. 1729

22. Liu C, Yang F, Jin Y, Ma X, Cheng D, Li N and Tian S 2010 Org. Lett. 123832

23. Chu C, Huang W, Lu C, Wu P, Liu J and Yao C 2006 Tetrahedron Lett. 477375

24. Iwanami K, Aoyagi M and Oriyama T 2005 Tetrahedron Lett. $\mathbf{4 6} 7487$

25. Karamé I, Alamé M, Kanj A, Baydoun G N, Hazimeh H, Masri M and Christ L 2011 C. R. Chim. 14525

26. Elinson M N, Ilovaisky A I, Merkulova V M, Barba F and Batanero B 2008 Tetrahedron 645915

27. Sahu R, Fulwa V K, Jena H S and Manivannan V 2012 Polyhedron 339 
28. Sahu R, Padhi S K, Jena H S and Manivannan V 2010 Inorg. Chim. Acta 3631448

29. Sheldrick G M 1996 SADABS, University of Göttingen, Göttingen, Germany

30. SMART and SAINT, Siemens Analytical X-ray Instruments Inc., Madison, WI, 1996

31. Sheldrick G M 2008 Acta. Cryst. A 64112

32. Ostendorf M, Romagnoli R, Cabeza Pereiro I C, Roos E C, Moolenaar M J, Speckamp W N and Hiemstra H 1997 Tetrahedron: Asymmetry 81773

33. Wocadlo S, Massa W and Folgado J 1993 Inorg. Chim. Acta. 207199

34. Bedford R B, Bruce D W, Frost R M, Goodby J W and Hird M 2004 Chem. Commun. 2822
35. Yamaguchi $Y$, Ando H, Nagaya M, Hinago H, Ito T and Asami M 2011 Chem. Lett. 40983

36. Addison A W, Rao T N, Reedijk J, van Rijn J and Verschor G C 1984 J. Chem. Soc. Dalton Trans. 1349

37. Small B L, Brookhart M and Bennett A M A $1998 J$. Am. Chem. Soc. 1204049

38. Britovsek G J P, Bruce M, Gibson V C, Kimberley B S, Maddox P J, Mastroianni S, McTavish S J, Redshaw C, Solan G A, Strömberg S, White A J $\mathrm{P}$ and Williams D J $1999 \mathrm{~J}$. Am. Chem. Soc. 121 8728

39. Mandon D, Machkour A, Goetz S and Welter R 2002 Inorg. Chem. 415364 